\title{
Multiple Downlink Fair Packet Scheduling Scheme in
}

\section{Wi-Max}

\author{
Pooja Gupta \\ Lingaya's University \\ Faridabad,India
}

\author{
Brijesh Kumar \\ Lingaya's University \\ Faridabad,India
}

\author{
B.L. Raina \\ Lingaya's University \\ Faridabad,India
}

\begin{abstract}
IEEE 802.16 is standardization for a broadband wireless access in network metropolitan area network (MAN). IEEE 802.16 standard (Wi-Max) defines the concrete quality of service (QoS) requirement, a scheduling scheme and efficient packet scheduling scheme which is necessary to achieve the QoS requirement. In this paper, a novel waiting queue based on downlink bandwidth allocation architecture from a number of $\mathrm{rtps}$ schedule has been proposed to improve the performance of nrtPS services without any impaction to other services. This paper proposes an efficient QoS scheduling scheme that satisfies both throughput and delay guarantee to various real and non-real applications corresponding to different scheduling schemes for $\mathrm{k}=1,2,3,4$. Simulation results show that proposed scheduling scheme can provide a tight QoS guarantee in terms of delay for all types of traffic as defined in WiMax standards. This process results in maintaining the fairness of allocation and helps to eliminate starvation of lower priority class services. The authors propose a new efficient and generalized scheduling schemes for IEEE 802.16 broadband wireless access system reflecting the delay requirements.
\end{abstract}

\section{Keywords: QoS,IEEE 802.16,WiMax,rtps,nrtps,Fair Scheduling.}

\section{INTRODUCTION}

IEEE 802.16 based wireless access scheme (commonly known as WiMAX) is considered as one of the most promising wireless broadband access for communication networks in metropolitan areas today. Since IEEE802.16 standard defines the concrete quality of service(QoS) requirement, a scheduling scheme is necessary to achieve the QoS requisite level. Many Scheduling schemes have earlier been proposed with the purpose of throughput optimization and fairness enhancement. However, few scheduling algorithm support the delay requirement. Here delay refers to unpredictably longer time for packets to reach the destination due to unavailability of network resources. IEEE802.16 has strict delay requirement, the lower the delay the better the QoS. To achieve the objective of providing a fair and efficient allocation of bandwidth to all the services without much of the delay different algorithms have been proposed by taking care of different parameters. Moreover, we have four service classes of IEEE802.16 which have different delay requirements for example for UGS service class cannot tolerate delay, while for BE service class is delay tolerable.

Sometime the priority of service classes leads to the starvation problem for lower priority service class. The priority goes from higher to lower like UGS>rtps>nrtps>BE respectively. In [1], the authors propose a hybrid of Earliest Due Date (EDD) and Weighted Fair Queue (WFQ). In EDD, all the arriving packets get a deadline stamp and are scheduled according to the increasing order of deadlines. The algorithm intends to serve the real time traffic first and only if real time buffer is empty will they consider BE traffic. This will certainly lead to starvation of lower priority requests. In [3], the authors consider two types of queues. The first type is used to schedule data grants for UGS and allocate request opportunities for rtPS and nrtPS. These grants are scheduled in a first in first out (FIFO) manner. Once the first queue type has been served, the scheduler will consider the second type leading to scarcity. The authors in [4] propose an architecture consisting of three schedulers. The first scheduler is concerned with UGS, rtPS and ertPS flows. The second scheduler is concerned with flows requiring a minimum bandwidth mainly nrtPS. The third scheduler is used for BE traffic that comes into picture only when the first two schedulers have become free. In [5], the authors suggest downlink bandwidth allocation algorithms based on flow type and strict priority from highest to lowest - UGS, rtPS, nrtPS and BE. Here an Opportunistic fair scheduling was used. Here $\mathrm{BE}$ traffic is served whenever an opportunity is available, but for most of the time BE starves for bandwidth. For guaranteeing the QoS for different service classes, priority based schemes could be used in WiMAX scheduler [6]. The priority order used in real time schedulers is: UGS, ertPS, rtPS, nrtPS and BE. Here the priority is maintained but the least priority ones starve for bandwidth. Delay based algorithm is specifically designed for both real time traffic and non real time traffic, where the delay tolerance is the primary QoS parameter. Earliest Due Date (EDD) is the basic algorithm for scheduler to serve the connection based on the deadline [7, 12]. However, this algorithm does not guarantee the throughput for higher priority service viz.UGS. So [13] proposed a scheduler that combines both EDD and priority for assuring nrtPS and BE better performance while trying to satisfy the other classes. Even though there are lots of conventional scheduling algorithms they are not meeting all 
the required QoS parameters. The performance affecting parameters like fairness, bandwidth allocation, throughput, average delay and delay jitter are studied and found out that none of the algorithms perform effectively for delay requirement of nrtps service class connections with respect to other service classes.

\section{SYSTEM MODEL}

Point to Multi Point(PMP) mode and mesh mode are the two types of operating modes define for IEEE802.16. In the PMP mode SSs are geographically scattered around the BS. The performance of IEEE 802.16 in the PMP mode is verified in[8][9]. Our system model is based on a time-division-duplex (TDD) mode. The IEEE 802.16 frame structure is illustrated in Fig.1[2]. The downlink subframe starts with preamble followed by frame control header (FCH), downlink map (DLMAP), uplink map (UL-MAP) messages and downlink burst data. The DLMAP message defines the start time, location, size and encoding type of the downlink burst data which will be transmitted to the SSs. Since the BS broadcasts the DLMAP message, every SS located within the service area decodes the DL-MAP message and searches the DL-MAP information elements (IEs) indicating the data bursts directed to that SS in the downlink subframe. After the transmit/receive transition gap (TTG), the uplink subframe follows the downlink subframe. IEEE 802.16 provides many advanced features like adaptive modulation coding (AMC), frame fragmentation and frame packing. In the current work, the focus is on the downlink scheduling scheme.

\section{MULTI USER SCHEDULER OF THE MAC LAYER}

In this section, a multiuser scheduler is designed at the medium access control (MAC) layer. Delay requirement is taken into account in the scheduler design. The AMC, packet fragmentation and packet packing have not been considered. In case of the UGS traffic, the required bandwidth is reserved in advance. Hence, only rtPS, nrtPS and BE connections are focused in the design.

\subsection{Proportional Fair Scheduling}

The proportional fair scheduling [10] has shown an impressive guideline in scheduler design because it maximizes the total sum of each SS's utility. In the proportional fair scheduling, the metric for each connection is defined as follows

$$
\phi_{i}(t)=D R C_{i}(t) / R_{i}(t) .
$$

where $\mathrm{DRC}_{\mathrm{i}}$ [12] is the rate requested by the $\mathrm{SS}_{\mathrm{i}}$ and $\mathrm{R}_{\mathrm{i}}$ is the average rate received by the $\mathrm{SS}_{\mathrm{i}}$ over a window of the appropriate size Tc [2][12]. The average rate $R_{i}$ is updated as

$$
\mathrm{R}_{\mathrm{i}}(\mathrm{t}+1)=\left(1-1 / \mathrm{T}_{\mathrm{c}}\right) \mathrm{R}_{\mathrm{i}}(\mathrm{t})+1 / \mathrm{T}_{\mathrm{c}} \text { *current transmission rate. }
$$

where Tc is the window size to be used in the moving average. The proportional fair scheduler selects the connection that has the highest metric value.

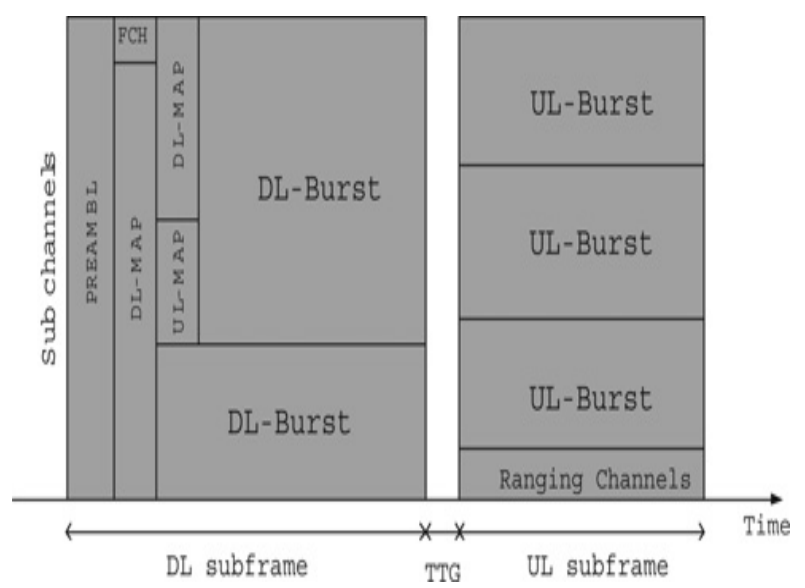

Fig. 1. IEEE 802.16[2] frame structure

\subsection{Proposed Fair Scheduling $(F S)$}

In the proportional fair scheduling, the strict fairness is guaranteed, however the QoS requirement is not reflected. To the knowledge of authors rtps connections for QoS have been discussed in the literature with regard to one specified nrtps connection ,Kim et. al.[2].Pooja gupta et al. [14]have generalized this concept by associating various parameters such as scheduling ratio $\mathrm{xi}$ of rtps class parameter associated to $\mathrm{k}$ number of nrtps class.Thus, the general scheduling scheme is being introduced that satisfies the delay requirement. In this paper we have generated a number of fair scheduling schemes corresponding to the parameter $\mathrm{k}$ so that the delay requirements are minimized with regard to corresponding nrtps schemes as mentioned below.

The metric value of the rtPS connections with the delay requirement should be increased as the queuing delay increases because the scheduler selects the connection with the highest metric value with nrtps connections, because nrtps connections are in the lowest priority. For the above mentioned conditions the equations for rtps and ,nrtps are proposed by the authors in paper [2].Here we are generalizing the above equation by proposing a new scheduling scheme based on the following metrics for rtPS, nrtPS and BE connections are given as :

$\Phi_{\mathrm{rt}, \mathrm{i}}(\mathrm{t})=1 / \mathrm{R}_{\mathrm{rt}, \mathrm{i}}(\mathrm{t})+\mathrm{C}\left(1+2 / \pi^{*} \arctan (|\mathrm{d}|)\right)$. if $\mathrm{q}_{\mathrm{i}}>0$ and $\mathrm{d} \geq \mathrm{d}_{\min }$. 


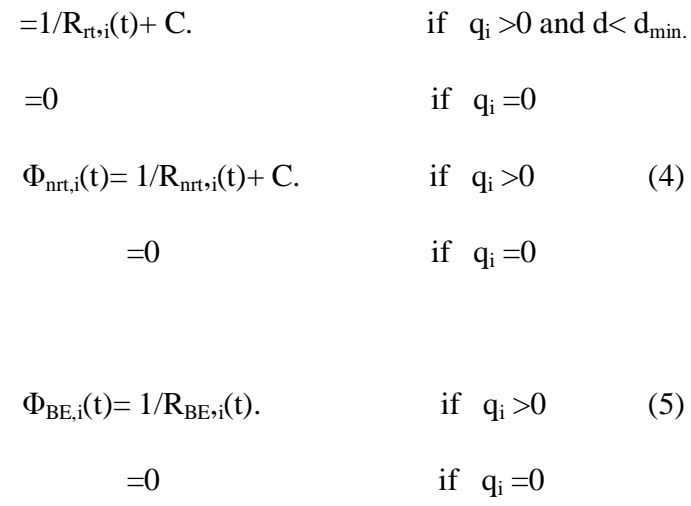

The parameter $\mathrm{d}$ is the queuing delay and $\mathrm{C}$ means the intensity of the delay requirement in the rtPS connection. The parameter dmin is the minimum delay that triggers the service differentiation between the rtPS connection and nrtPS connection, and $q_{i}$ means the queue length of the connection $i$. Note that $R_{r t}, R_{n r t}$ and $R_{B E}$ are updated in the same manner as in the proportional fair scheduling, that is

$\mathrm{R}_{\mathrm{rt}, \mathrm{i}}(\mathrm{t}+1)=\left(1-1 / \mathrm{T}_{\mathrm{c}}\right) \mathrm{R}_{\mathrm{rt}, \mathrm{i}}(\mathrm{t})+\mathrm{r} / \mathrm{T}_{\mathrm{c}}$ if connection $i$ is scheduled.

$$
\left.=\left(1-1 / \mathrm{T}_{\mathrm{c}}\right) \mathrm{R}_{\mathrm{rt}}, \mathrm{i} \mathrm{t}\right) \quad \text { otherwise }
$$

where Tc is the window size to be used in the moving average and $r$ is the current transmission rate requested by the SS. The long-term rate is the average sum of the previously scheduled transmission rates during the time window $\mathrm{Tc}$, where the high Tc value means that the long-term rate changes slowly because the average is taken over many previous transmission rates. The long-term rate of a connection decreases exponentially before the connection is scheduled, and it increases when the connection is scheduled. We do not consider the AMC, so $r$ is a constant. On every frame, the scheduler selects the connection that has the highest metric value. Owing to the delay requirement term in the rtPS metric, rtPS connections are served more frequently than other connections when the queuing delay increases.

\subsection{Determination of Novel Parameters with Analysis}

The scheduling ratio $\mathrm{x}$ as the average number of scheduling times for each of rtPS to $\mathrm{k}$ nrtPS connections where $\mathrm{k}<=\mathrm{x}$ has been defined as given by the following two cases:

If rtPS and nrtPS connections are scheduled equally, the scheduling ratio $\mathrm{x}$ equals $\mathrm{k}$, and if rtPS connection is scheduled more frequently than nrtPS connection, the scheduling ratio $\mathrm{x}$ becomes greater than $\mathrm{k}$. Now the average scheduling interval in the rtPS connection is $((\mathrm{x}+\mathrm{k}) / \mathrm{x})$ frames because, on the average, $\mathrm{k}$ nrtPS schedule corresponding to $\mathrm{x}$ rtPS connections. As a result of this, the average scheduling interval in nrtPS connection is $(\mathrm{k}+\mathrm{x})$ frames. At the steady state, the average long-term rates of rtPS and nrtPS connections at the scheduling instance are as follows:

$$
\begin{aligned}
& \overline{R_{r t}}=\overline{R_{r t}}\left(1-\left(1 / \mathrm{T}_{\mathrm{c}}\right)\right)^{(\mathrm{k}+\mathrm{x}) / \mathrm{x}}+(\mathrm{r} / \mathrm{Tc}), \text { at the steady state, we } \\
& \text { obtain }
\end{aligned}
$$

$$
\overline{R_{r t}}=\left(\mathrm{r} / \mathrm{T}_{\mathrm{c}}\right) /\left(1-\left(1-\left(1 / \mathrm{T}_{\mathrm{c}}\right)\right)^{(\mathrm{k}+\mathrm{x}) / \mathrm{x}}\right.
$$

Analogously, Since $\overline{R_{n r t}}=\overline{R_{n r t}}\left(1-\left(1 / \mathrm{T}_{\mathrm{c}}\right)\right)^{(\mathrm{k}+\mathrm{x})}+(\mathrm{r} / \mathrm{Tc})$ at the steady state, we obtain

$$
\overline{R_{n r t}}=\left(\mathrm{r} / \mathrm{T}_{\mathrm{c}}\right) /\left(1-\left(1-\left(1 / \mathrm{T}_{\mathrm{c}}\right)\right)^{(\mathrm{k}+\mathrm{x})}\right.
$$

We consider the same assumption as in [11] that the average metric value for each connection at the scheduling instance becomes similar to each other. Hence,

$\mathrm{C}(1+(2 / \pi) \arctan (\mathrm{d}))$.

$$
1 / \overline{R_{r t}}\left(1-\left(1 / \mathrm{T}_{\mathrm{c}}\right)\right)^{(\mathrm{k}+\mathrm{x}) / \mathrm{x}}
$$

$$
\approx 1 / \overline{R_{n r t}}\left(1-\left(1 / \mathrm{T}_{\mathrm{c}}\right)\right)^{(\mathrm{k}+\mathrm{x})}+\mathrm{C} \text {. }
$$

From (7) and (8), (9) can be written as

$$
\begin{gathered}
\quad\left(1-\left(1-\left(1 / \mathrm{T}_{\mathrm{c}}\right)\right)^{(\mathrm{k}+\mathrm{x}) / \mathrm{x}}\right)^{*} \mathrm{~T}_{\mathrm{c}} /\left(\mathrm{r}^{*}\left(1-\left(1 / \mathrm{T}_{\mathrm{c}}\right)\right)^{(\mathrm{k}+\mathrm{x}) / \mathrm{x}}\right)+ \\
\left.\approx\left(1-\left(1-\left(1 / \mathrm{T}_{\mathrm{c}}\right)\right)^{(\mathrm{k}+\mathrm{x})}\right) *(2 / \pi) \arctan (\mathrm{d})\right) \mathrm{T}_{\mathrm{d}} /\left(\mathrm{r}^{*}\left(1-\left(1 / \mathrm{T}_{\mathrm{c}}\right)\right)^{(\mathrm{k}+\mathrm{x})}\right)+\mathrm{C} .
\end{gathered}
$$

Put $\left(1-1 / T_{c}\right)=X, L=1+(2 / \pi) \arctan (d)$, therefore from above equation we have

$$
\begin{gathered}
\left(1-(\mathrm{X})^{(\mathrm{k}+\mathrm{x}) / \mathrm{x}}\right) * \mathrm{~T}_{\mathrm{c}} /\left(\mathrm{r}^{*}\left(\mathrm{X}^{(\mathrm{k}+\mathrm{x}) / \mathrm{x}}\right)+\mathrm{C} * \mathrm{~L}\right. \\
\left(1-(\mathrm{X})^{(\mathrm{k}+\mathrm{x})}\right) * \mathrm{Tc} /\left(\mathrm{r}^{*}\left(\mathrm{X}^{(\mathrm{k}+\mathrm{x})}\right)+\mathrm{C}\right. \\
\text { i.e. } \mathrm{C}^{*}(\mathrm{~L}-1)=(\mathrm{Tc} / \mathrm{r})^{*}\left(\left(1-(\mathrm{X})^{(\mathrm{k}+\mathrm{x})} / \mathrm{X}^{(\mathrm{k}+\mathrm{x})}-\left(1-(\mathrm{X})^{(\mathrm{k}+\mathrm{x}) / \mathrm{x}}\right) / \mathrm{X}^{(\mathrm{k}+\mathrm{x}) / \mathrm{x}}\right)\right) \\
\mathrm{C}^{*}(2 / \pi)^{*} \tan ^{-1} \mathrm{~d}=(\mathrm{Tc} / \mathrm{r})^{*}\left(\left(\mathrm{X}^{(\mathrm{k}+\mathrm{x}) / \mathrm{x}}-\mathrm{X}^{(\mathrm{k}+\mathrm{x})}\right) / \mathrm{X}^{\left(\left(\mathrm{x}^{*} \mathrm{x}+\mathrm{k}^{*} \mathrm{x}+\mathrm{k}+\mathrm{x}\right) / \mathrm{x}\right)}\right)
\end{gathered}
$$

Now with the help of $\mathrm{L}$ and $\mathrm{X}$ as defined above and with little algebra, the set of values of delay represented by $d=d_{i}$ correspond to different sets of values of $\mathrm{x}, \mathrm{k}$ and $\mathrm{C}$, from equation (11) we have for $\mathrm{d} \geq 0$,

$$
\begin{aligned}
& \mathrm{d}=\tan \left(\left(\left(\pi^{*} \mathrm{Tc}\right) /\left(2 * \mathrm{r}^{*} \mathrm{C}\right) *\left[\left((1-1 / \mathrm{Tc})^{(\mathrm{k}+\mathrm{x}) / \mathrm{x}}-(1-1 / \mathrm{Tc})^{(\mathrm{k}+\mathrm{x})}\right)\right] /(1-\right.\right. \\
& \left.1 / \mathrm{Tc})^{\left(\left(\mathrm{x}^{*} \mathrm{x}+\mathrm{k}^{*} \mathrm{x}+\mathrm{k}+\mathrm{x}\right) / \mathrm{x}\right)}\right](12)
\end{aligned}
$$

Now generalizing the above equation if $d_{i}$ represents the various delays for $\mathrm{i}$ iterations corresponding to the above parameters associated to number of rtps,nrtps and intensity such that $d \geq 0$. Thus we have the main result as :

$$
\begin{aligned}
& \mathrm{d}_{\mathrm{i}}=\tan \left(\left(\left(\pi^{*} \mathrm{Tc}\right) /(2 * \mathrm{r} * \mathrm{C}) *\left[\left((1-1 / \mathrm{Tc})^{(\mathrm{k}+\mathrm{x}) / \mathrm{x}}-(1-1 / \mathrm{Tc})^{(\mathrm{k}+\mathrm{x})}\right)\right] /(1-\right.\right. \\
& \left.1 / \mathrm{Tc})^{\left(\left(\mathrm{x}^{*} \mathrm{x}+\mathrm{k}^{*} \mathrm{x}+\mathrm{k}+\mathrm{x}\right) / \mathrm{x}\right)}\right] \text {, However } \mathrm{d}_{\mathrm{i}} \geq 0
\end{aligned}
$$

here $\mathrm{x}_{\mathrm{i}}=\mathrm{i}, 0 \leq \mathrm{i} \leq 10$. However, $\mathrm{d}_{\mathrm{i}}, \mathrm{C}_{\mathrm{j}}, \mathrm{k}_{\mathrm{t}}$ all will take real values under the investigation as given below:

Now we determined the solution set $\left(\mathrm{d}_{\mathrm{i}}\right)$ corresponding to the various parameters $C_{j}, x_{i}$ and $k_{t}$. As the parameter $C_{i}$ 
increases, the delay $d_{i}$ decreases because $d_{i}$ and $C_{i}$ are inversely proportional to each other. For, $\mathrm{k}=1$, we derive the delays $d_{i}$ corresponding to different values of $C=C_{i}$ and plot the graph as given below. When we compare these with the ones derived by Kim et. al.[2], we notice here that our results turn out to be almost closer with their results.

\section{SIMULATION RESULTS OF FOUR FAIR SCHEDULING SCHEMES}

We now compare the delays of rtPS and nrtPS corresponding to a number of scheduling schemes corresponding to $\mathrm{k}=1,2,3,4$ and as such analysis has been done using Matlab for values of di (delays) corresponding to different prescribed values of $\mathrm{x}_{\mathrm{i}}, \mathrm{k}_{\mathrm{t}}$, and $\mathrm{C}_{\mathrm{j}}$, for $1 \leq \mathrm{i} \leq 10, \mathrm{j}=1,2,3, \mathrm{t}=1,2,3,4$.

CASE I a) $x: k=1: 1$ that is number of rtps connections is equal to number of nrtps connections. In this case $x=5, k=5$.

Table 1. Delay requirement of $r$ ps connections for $k=1$ corresponding to various values of $C=C_{j}, 1 \leq j \leq 3$

\begin{tabular}{|l|l|l|l|l|l|l|l|l|l|l|l|}
\hline $\mathrm{x}$ & 1 & 2 & 3 & 4 & 5 & 6 & 7 & 8 & 9 & 10 & $\mathrm{C}_{j}$ \\
\hline $\mathrm{d}_{1}$ & .0029 & .0064 & .0098 & .0133 & .0167 & .0202 & .0237 & .0271 & .0306 & .0341 & 0.1 \\
\hline $\mathrm{d}_{2}$ & .0059 & .0128 & .0197 & .0266 & .0336 & .0405 & .0475 & .0546 & .0617 & .0689 & 0.05 \\
\hline $\mathrm{d}_{3}$ & .0002 & .03 & .0635 & .0877 & .1139 & .143 & .1761 & .215 & .2622 & .322 & 0.01 \\
\hline
\end{tabular}

We now draw the graph for delay $d_{i}, 1 \leq i \leq 10$, for various values of $\mathrm{x}$ corresponding to one nrtps scheduling i.e. $\mathrm{k}=1$ and compare these delays with the once obtained by Kim et. al.[2].The analysis follows as under:

Case I. 1

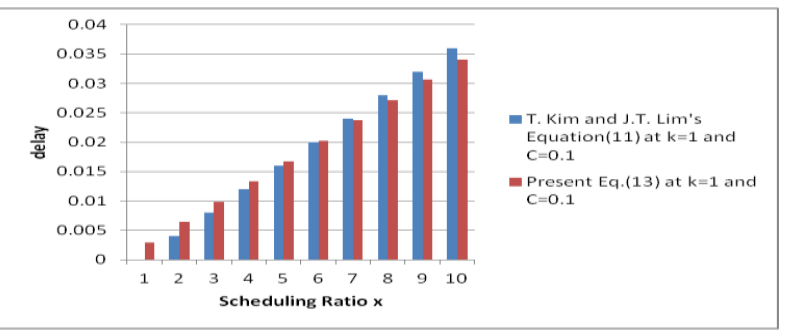

Fig 2. Delay against Scheduling ratio $x$ when $k=1$ at $C=0.1$

\section{Case I.2}

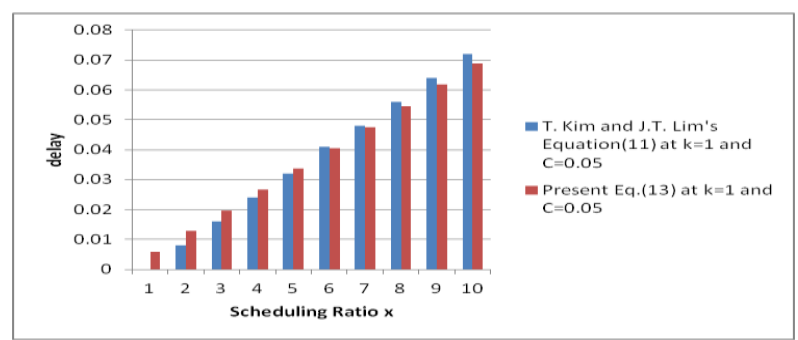

Fig 3. Delay against Scheduling ratio $x$ when $k=1$ at $\mathbf{C}=\mathbf{0 . 0 5}$

Case I.3

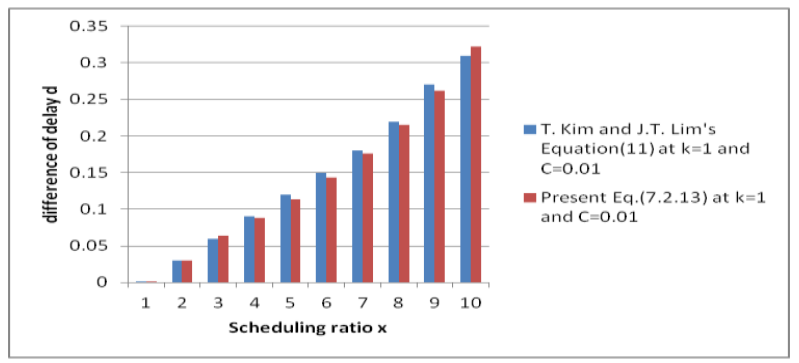

Fig 4. Delay against Scheduling ratio $x$ when $k=1$ at $\mathbf{C}=\mathbf{0 . 0 1}$

From Fig. 2., Fig. 3. and Fig. 4, it has been observed that our Eq.(13) coincides with Kim et. al. equation[2]'s equation. Hence our equations proves to be correct for $\mathrm{k}=1$ at $\mathrm{C}=0.1,0.05$ and 0.01.However, it has been analysed that as $\mathrm{x}$ increases, the delays corresponding to each of five rtPS, five nrtPS increase. However, we notice that for first five values of $\mathrm{x}$, respective delays of nrtPS.>rtPS and then there follows transition and for the next five values the delays reverse such that $\operatorname{nrtPS}<$ rtPS justifying doing away with the starvation of nrtps.

Case II:

Delay requirement of $\mathrm{rtps}$ connection for $\mathrm{k}=2$, such that $\mathrm{k} \leq \mathrm{x}$.

Table 2. Delay requirement of $r$ ps connections for $\mathrm{k}=2$ corresponding to various values of $C=C_{j}, 1 \leq j \leq 3$

\begin{tabular}{|l|l|l|l|l|l|l|l|l|l|l|l|}
\hline $\mathrm{x}$ & 1 & 2 & 3 & 4 & 5 & 6 & 7 & 8 & 9 & 10 & $\mathrm{C}_{\mathrm{j}}$ \\
\hline $\mathrm{d}_{1}$ & .0169 & .0267 & .0366 & .0464 & .0563 & .0662 & .0761 & .0861 & .0960 & .1060 & 0.1 \\
\hline $\mathrm{d}_{2}$ & .0337 & .0534 & .0732 & .0930 & .1130 & .1330 & .1531 & .1734 & .1939 & .2145 & 0.05 \\
\hline $\mathrm{d}_{3}$ & .1701 & .2734 & .3825 & .5003 & .6304 & .7779 & .9501 & 1.1583 & 1.4206 & 1.7693 & 0.01 \\
\hline
\end{tabular}

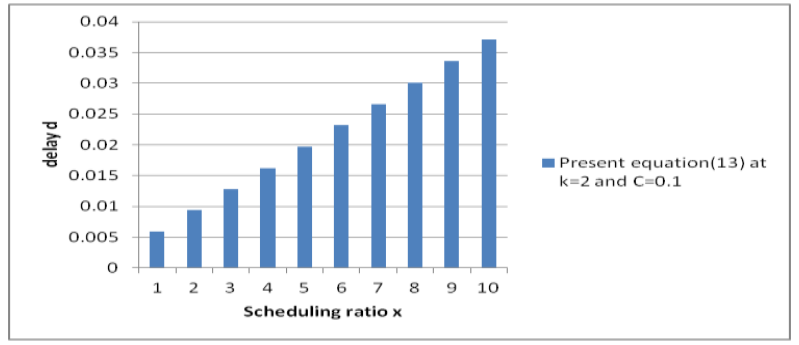

Fig 5. Delay against Scheduling ratio $x$ when $k=2$ at $C=0.1$ 


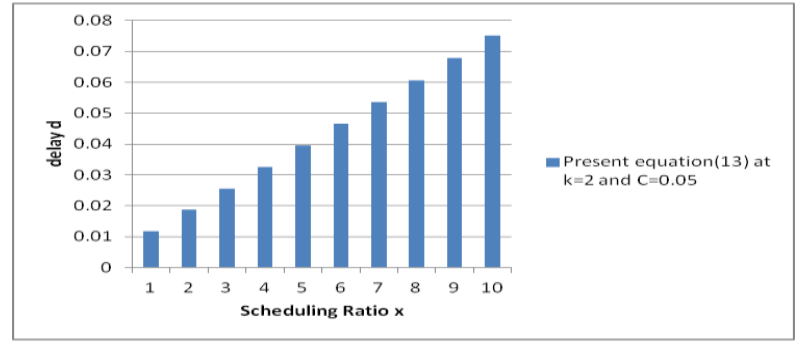

Fig 6. Delay against Scheduling ratio $x$ when $k=2$ at $\mathbf{C}=\mathbf{0 . 0 5}$

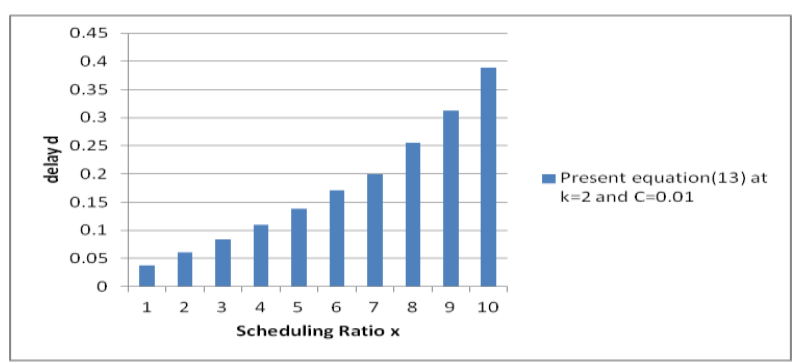

Fig 7. Delay against Scheduling ratio $x$ when $k=2$ at $\mathbf{C}=\mathbf{0 . 0 1}$

Case III:

Delay requirement of $\mathrm{rtps}$ connection for $\mathrm{k}=3$, such that $\mathrm{k} \leq \mathrm{x}$.

Table 3. Delay requirement of $r$ tps connections for $k=3$ corresponding to various values of $C=C_{j}, 1 \leq j \leq 3$

\begin{tabular}{|l|l|l|l|l|l|l|l|l|l|l|l|}
\hline $\mathrm{x}$ & 1 & 2 & 3 & 4 & 5 & 6 & 7 & 8 & 9 & 10 & $\mathrm{C}_{3}$ \\
\hline $\mathrm{d}_{\mathrm{1}}$ & .0253 & .0351 & .0450 & .0549 & .0648 & .0747 & .0847 & .0946 & .1046 & .1146 & 0.1 \\
\hline $\mathrm{d}_{2}$ & .0506 & .0704 & .0902 & .1101 & .1301 & .1503 & .1705 & .1910 & .2115 & .2323 & 0.05 \\
\hline $\mathrm{d}_{3}$ & .2584 & .3665 & .4829 & .6109 & .7556 & .9238 & 1.1259 & 1.3791 & 1.7127 & 2.1834 & 0.01 \\
\hline
\end{tabular}

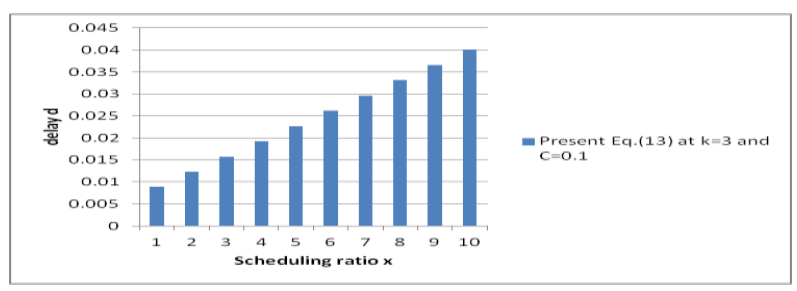

Fig 8. Delay against Scheduling ratio $x$ when $k=3$ at $C=0.1$

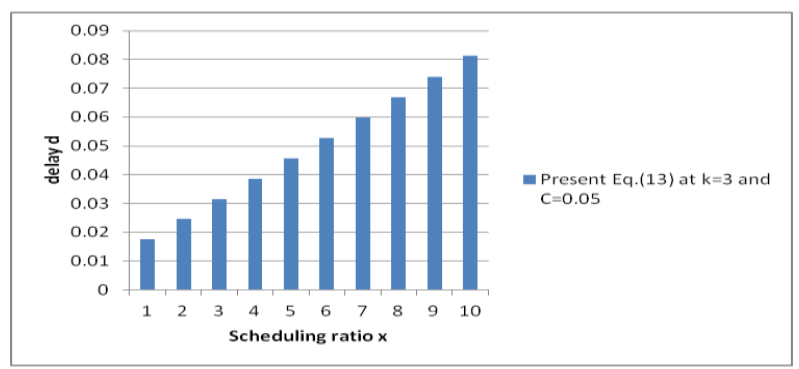

Fig 9. Delay against Scheduling ratio $x$ when $k=3$ at $\mathrm{C}=\mathbf{0 . 0 5}$

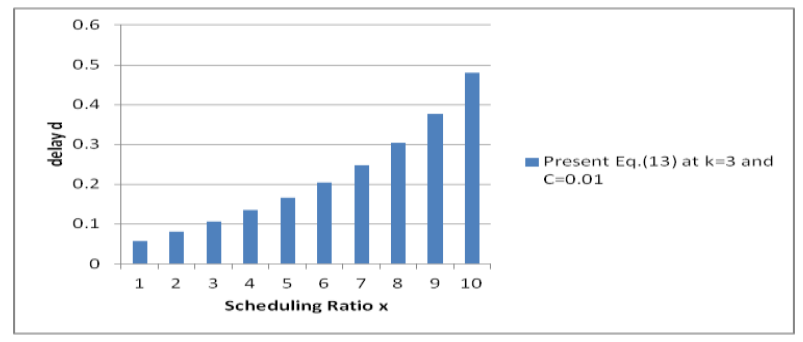

Fig 10. Delay against Scheduling ratio $x$ when $k=3$ at $\mathbf{C}=\mathbf{0 . 0 1}$

Case IV:

Delay requirement of $\mathrm{rtps}$ connection for $\mathrm{k}=4$, such that $\mathrm{k} \leq \mathrm{x}$.

Table 4. Delay requirement of rtps connections for $\mathrm{k}=4$ corresponding to various values of $C=C_{j}, 1 \leq j \leq 3$

\begin{tabular}{|l|l|l|l|l|l|l|l|l|l|l|l|}
\hline $\mathrm{x}$ & 1 & 2 & 3 & 4 & 5 & 6 & 7 & 8 & 9 & 10 & $\mathrm{C}_{\mathrm{j}}$ \\
\hline $\mathrm{d}_{1}$ & 0.0117 & 0.0152 & 0.0187 & 0.0221 & 0.0256 & 0.0291 & 0.0326 & 0.0361 & 0.0396 & 0.0431 & 0.1 \\
\hline $\mathrm{d}_{2}$ & 0.0236 & 0.0305 & 0.0375 & 0.0445 & 0.0515 & 0.0586 & 0.0658 & 0.0728 & 0.0792 & 0.0876 & 0.05 \\
\hline $\mathrm{d}_{3}$ & 0.0771 & 0.1024 & 0.1301 & 0.1614 & 0.1975 & 0.2408 & 0.2946 & 0.3649 & 0.4630 & 0.6131 & 0.01 \\
\hline
\end{tabular}

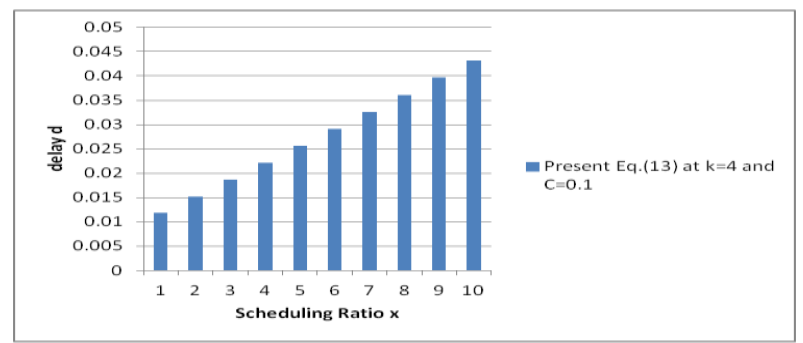

Fig 11. Delay against Scheduling ratio $x$ when $k=4$ at $\mathrm{C}=\mathbf{0 . 1}$

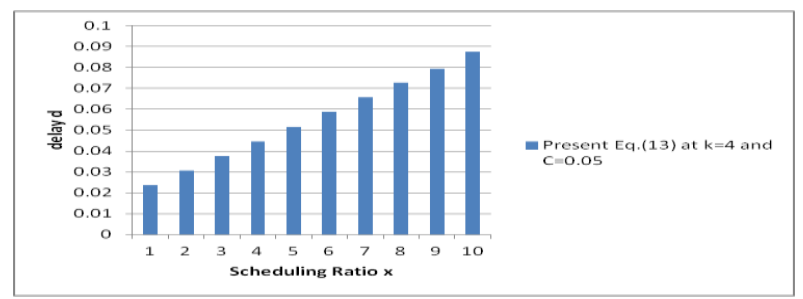

Fig 12. Delay against Scheduling ratio $x$ when $k=4$ at $\mathbf{C}=\mathbf{0 . 0 5}$ 


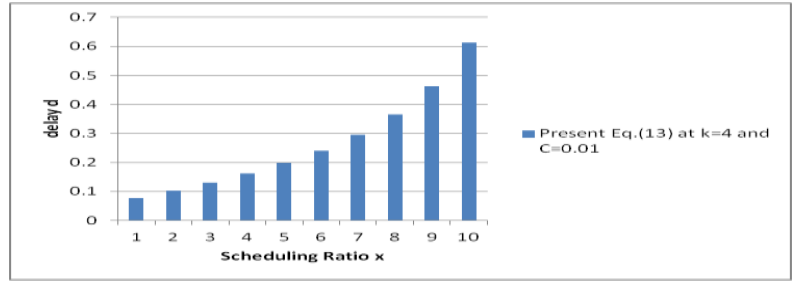

Fig 13. Delay against Scheduling ratio $x$ when $k=4$ at $\mathbf{C}=\mathbf{0 . 0 1}$

Table 5. Simulation Information

\begin{tabular}{|l|l|}
\hline Parameter & Value \\
\hline Packet Size & 1500 bytes \\
\hline Number of nodes & 10 \\
\hline Delay requirement & $30 \mathrm{~ms}$ \\
\hline
\end{tabular}

Table 6. represent the comparison of all the analysis that has been observed for Kim et. al.[2] value's at $k=1$.Our's at $\mathrm{k}=1,2,3,4$ at different values of $\mathrm{C}$ corresponding to different values of $\mathrm{x}$ where $1 \leq \mathrm{x} \leq 10$.

Table 6. Anaylsis of result of Kim et. al. at $k=1$,Our's at $k=1, k=2, k=3$ and $k=4$ at different values of $\mathrm{C}$ corresponding to different values of $x$ where $1 \leq x \leq 10$.

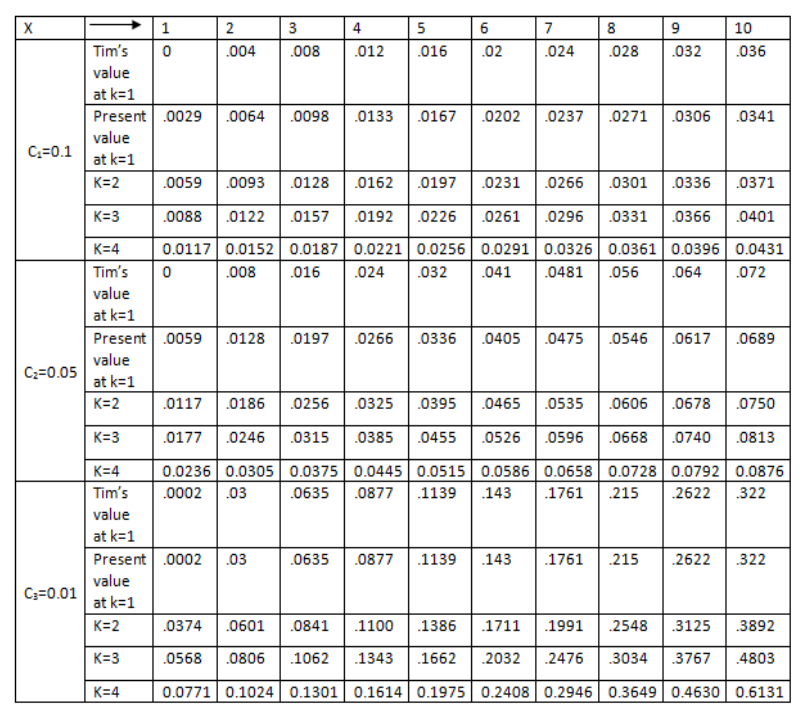

\section{ANALYSIS OF DELAYS OF rtps and nrtps SERVICE CLASSES}

Now in particular, we give the comparison of delay of different classes with regard to the 10 nodes for the cases $\mathrm{C}=$ $0.1, \mathrm{C}=.05$ and $\mathrm{C}=0.01 \mathrm{Kim}$ et. al.[2] at $\mathrm{k}=1$ with our's
Equation(13) and analyze the comparison of the downlink services within rtPS, nrtPS, as given below:

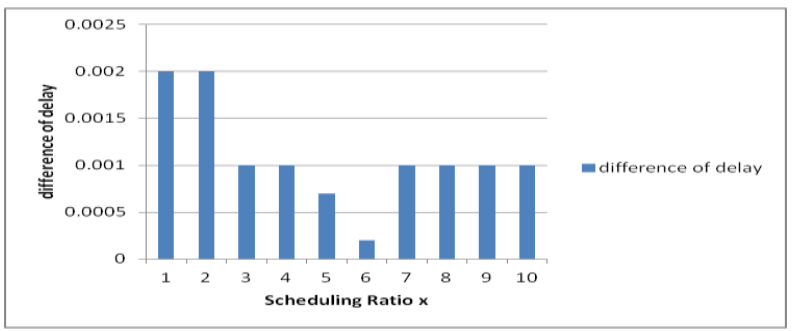

Fig. 14. Difference of delay $d$ of Kim et. al.[2] with our's Equation(13) when $\mathrm{k}=1$ and $\mathrm{C}=0.1$

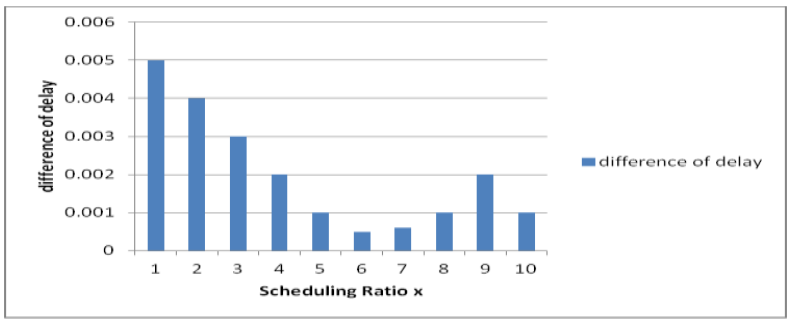

Fig. 15. Difference of delay d of Kim et. al.[2] with our's Equation(13) when $\mathrm{k}=1$ and $\mathrm{C}=\mathbf{0 . 0 5}$

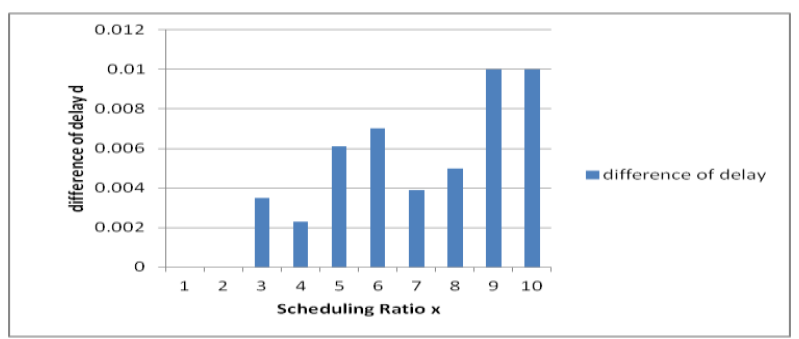

Fig. 16. Difference of delay d of Kim et. al.[2] with our's Equation(13) when $\mathrm{k}=1$ and $\mathrm{C}=\mathbf{0 . 0 1}$

From Fig. 14, it has been observed that the difference of delay when $\mathrm{k}=1$ and $\mathrm{C}=.1$ first decreases till sixth value of $\mathrm{x}$ and then become steady. The value of difference of delay is approx. 0.001 which is quite less. Similarly, from Fig. 15 it has been observed that the difference of delay when $\mathrm{k}=1$ and $\mathrm{C}=0.05$ first decreases till sixth value of $\mathrm{x}$ then increases and decreases at 10 but again the value of difference of delay is quite less. From Fig. 16 it has been observed that the difference of delay when $\mathrm{k}=1$ and $\mathrm{C}=.01$ is showing the variation of increase and decrease but that will not not effect much because of the lesser difference.

\section{CONCLUSION}

In this paper, an effort has been done to remove the starvation problem and improvise the proportional fair scheduling scheme by managing the value of $\mathrm{k}$. The suggested model has been simulated using Matlab and the results have 
been discussed. To support the QoS requirement the delay requirement term in the proportional fair scheduling scheme has been added. The main contribution of this paper is that a method has been proposed which will generalize the delay requirement by associating various parameters of $\mathrm{x}_{\mathrm{i}}$ defined as (various) rtps connections to the parameter $\mathrm{k}_{\mathrm{i}}$ associated to the (various) nrtps connections. The suggested general scheduling scheme satisfies the delay requirement. One can find the appropriate parameter $\mathrm{C}$ according to the traffic condition of the networks. After fine tuning of the operating parameter, the delay requirement can be satisfied without excessive sacrifice in the nrtps connection performance.

\section{REFERENCES}

[1]. Guojun D., Dai J., (March 2007), “An Improved Handover Algorithm for Scheduling Services in IEEE802.16e", Published in Mobile WiMAX Symposium,Orlando,FL, IEEE,pp 38-42.

[2]. Kim T., Lim J.T.,"Quality of service supporting downlink scheduling scheme in worldwide interoperability for microwave access wireless access systems", Published in IET.Communications, Vol. 4, Iss. 1, pp. 32-38,2010.

[3]. Howon L. , Taesoo K. and Dong-Ho Cho, (Sept. 2004), "An efficient uplink scheduling algorithm for VoIP services in IEEE 802.16 BWA systems", 60th IEEE Vehicular Technology Conference, vol.5, pp. 3070 3074.

[4]. Kun y., Jie z. and Hsiao-hwa c., (March-April2007), “A Flexible QoS aware service Gateway for heterogeneous wireless networks",Published in IEEE NETWORK, vol. 21,issue 2,pp 6-12 .

[5]. Mehrjoo M.,Dianati M., Shen X. and Naik K.,(2006), "Opportunistic Fair Scheduling for the Downlink of IEEE 802.16Wireless Metropolitan Area Networks", Published in Proceeding Qshine'06 proceedings of the 3rd International Conference on QoS in heterogenous Wired /Wireless Networks, vol.191.

[6]. Wang Y., et al., (May 2008), "Priority-Based Fair scheduling for Multimedia WiMAX Uplink Traffic", Proc. of IEEE International Conference on Communication, China.

[7]. Perumalraja R., et al., (2006), "Multimedia Supported Uplink Scheduling for IEEE 8021.6d OFDMA Networks", Proceedings of Annual India Conference.

[8]. Kumar S.,"Hybrid scheduling For QoS in WiMAX”,Master Thesis, Thapar University,Patiala,June 2009.

[9]. "IEEE Standard for Local and metropolitan area networks", Part 16: Air Interface for Broadband Wireless Access Systems.

[10]. CDMA-HDR a high efficiency-high data rate personal communication wireless system'. Proc. IEEE Vehicle Technology Conf., Tokyo, May 2000, vol. 3,pp. 1854-1858.
[11]. HOU F., HO P., SHEN X., CHEN A. “A novel QoS scheduling scheme in IEEE 802.16 networks". Proc. IEEE WCNC, Hong Kong, March 2007, pp. 2457-2462.

[12]. Wongthavarawat K., and Ganz A., (2003), "Packet Scheduling for QoS Support in IEEE 802.16 Broadband Wireless Access Systems", International Conference. on Journal of Commn. Systems., pp.81-86.

[13]. Perumalraja R., et al., (Sept. 2010), "QoS Assured Uplink Scheduler for WiMAX Networks", Published in Vehicular Technology Conference Fall,IEEE 72 ${ }^{\text {nd }}$,pp-1-5.

[14]. Gupta P., Kumar B., Raina B.L.,"QoS Support downlink for WiMAX Network", Published in QSHINE 2013,LNICST(Lecture Notes of the Institute for Computer Sciences, Social Informatics and Telecommunications Engineering) Springer 115 proceeding ,pp- 989-997. 